\title{
PEMETAAN ANGKA KEAMANAN LERENG BERDASARKAN DATA HUJAN (STUDI KASUS : BUKIT GANOMAN, DESA KORIPAN, KECAMATAN MATESIH, KABUPATEN KARANANYAR)
}

Pengkuh Jalu Kurniawann) R. Harya Dananjaya ${ }^{2)}$ Rr. Rintis Hadiani ${ }^{3}$ )

1)Mahasiswa Fakultas Teknik, Program Studi teknik Sipil, Universitas Sebelas Maret

2),3) Pengajar Fakultas Tenik, Program Studi teknik Sipil, Universitas Sebelas Maret

Jln Ir. Sutami 36A, Surakarta 57126; Telp. 0271-634524.

Email : jalukurniawan5@gmail.com

\begin{abstract}
Due to 34 locations in 8 districts in Karanganyar are identified as prone to landslides, Karanganyar is one of the regencies in Central Ja$v a$ that is classified as landslide-prone area. Rain is one of the factors that can affect the stability of the slope. The high intensity of rainfall $>100$ $\mathrm{mm} /$ day) can trigger the occurrence of landslides, because the infiltrated water causes soil mass increas and soil strenght decrease.The purpose of this research is to create landslide risk map of Ganoman bill under influence of rainfall.

The soil data used in this study was primary soil data obtained from the undisturbed soil samples and the secondary soil data taken from the previous research at the same location. The used rainfall data was two day maximum rainfall data during 2015 and 2016 from Matesih and Karanganyar rain stations. The intensity of rainfall was assumed to be 6 hours a day. The elevation and slope data was obtained from ASTER GDEM Karanganyar. The saturated soil thickness due to the rainfall infiltration was calculated using the Green-Ampt method. The slope stability was calculated using GeoStudio Slope/W software. And then the SF obtained from Geostudio Slope/W was plotted to the map, so that the landslide risk map is created.

The result of this research shows that Ganoman hill has slope variation range from 0 to $45^{\circ}$. Also, maximum two-day rainfall during 2015 and 2016 is 17,219 mm/ hour. It causes wetting front $\left(H_{\text {sat }}\right)$ to range from 3,8 to 5,48 meters. According to Bowles (1989) the slope classification of Ganoman hill are: 1) The Stable slopes located in slopes with angle from $0^{\circ}$ to $30^{\circ}$,2) the critical slopes located in slopes with angle from $31^{\circ}$ to $35^{\circ}$, and 3) the unstable slopes located on slopes with angle from $36^{\circ}$ to $45^{\circ}$.
\end{abstract}

Keywords: Landslide, Green-Ampt, GeoStudio, SF Map, GIS.

\begin{abstract}
Abstrak
Karanganyar merupakan salah satu Kabupaten di Jawa Tengah yang tergolong sebagai lokasi rawan longsor, sebanyak 34 titik di 8 kecamatan di Kabupaten Karanganyar teridentifikasi rawan longsor. Salah satu faktor yang mempengaruhi kestabilan lereng adalah hujan. Hujan dengan intensitas tinggi ( $>100 \mathrm{~mm} /$ hari) dapat memicu terjadinya longsor, hal tersebut dikarenakan air hujan yang terinfiltrasi kedalam tanah menyebabkan proses penjenuhan tanah sehingga massa tanah meningkat. Tujuan penelitian ini adalah untuk membuat peta angka keamanan lereng akibat pengaruh hujan dan sudut kemiringan dilokasi bukit Ganoman, Desa Koripan, Kecamatan Matesih, Kabupaten Karanganyar.

Data tanah yang digunakan pada penelitian ini adalah data tanah primer yang diperoleh dari sampel tanah tidak terganggu dan data sekunder tanah yang diambil dari penelitian sebelumnya di lokasi yang sama. Data hujan yang digunakan adalah data hujan dua harian maksimum selama tahun 2015 dan 2016 dari stasiun hujan Matesih dan Karanganyar. Asumsi lama hujan yang terjadi adalah hujan 6 jam-an. Data variasi kemiringan diperoleh dari ASTER GDEM Kabupaten Karanganyar. Ketebalan tanah jenuh akibat infiltrasi air hujan dihitung menggunakan metode Green-Ampt. Stabilitas lereng dihitung menggunakan software GeoStudio Slope/W. Dan kemudian SF yang diperoleh dari Geostudio Slope/W diplotkan ke peta Rupa Bumi sehingga didapatkan peta risiko longsor.

Dari hasil penelitian diketahui bukit Ganoman memiliki variasi kemiringan lereng berkisar antara 0 hingga 45 derajat dan hujan dua harian maksimum yang terjadi pada tahun 2015 dan 2016 dengan intensitas hujan 6 jam-an adalah 17,219 $\mathrm{mm} / \mathrm{jam}$, sehingga menyebabkan ketebalan tanah jenuh $\left(H_{\text {sat }}\right)$ berkisar antara 3,8 hingga 5,48 meter. Berdasarkan kriteria Bowles (1989) klasifikasi lereng bukit Ganoman adalah : 1) Lereng dengan kondisi stabil, yaitu lereng yang mempunyai kemiringan $0^{\circ}$ hingga $30^{\circ}$, 2) lereng dengan kondisi kritis, yaitu lereng yang mempunyai kemiringan $31^{\circ}$ hingga $35^{\circ}$, dan 3 ) lereng dengan kondisi labil, yaitu lereng yang mempunyai kemiringan $36^{\circ}$ hingga $45^{\circ}$.
\end{abstract}

Kata kunci: Longsor, Green-Ampt, GeoStudio, Peta SF, SIG.

\section{PENDAHULUAN}

Longsor merupakan salah satu bencana alam geologi yang dapat menyebabkan banyak kerugian, baik korban jiwa maupun kerugian material yang cukup besar. Kejadian longsor di Indonesia biasanya banyak terjadi ketika musih hujan tiba. Secara umum terdapat dua tipe hujan yang dapat memicu terjadinya longsor di Indonesia, yaitu tipe hujan deras dan tipe hujan normal tetapi berlangsung lama.

Desa Koripan, Kecamatan Matesih, Kabupaten Karanganyar yang terletak di provinsi Jawa Tengah adalah daerah yang kondisi alamnya berupa perbukitan dan lereng batuan yang terjal. Daerah tersebut berpotensi besar mengalami kelongsoran. Banyak ditemukan titik-titik kelongsoran terutama setelah terjadi hujan. Oleh karena itu penelitian ini dilakukan agar dapat menjadi bahan pertimbangan dan acuan dalam mitigasi bencana longsor. 


\section{TINJAUAN PUSTAKA}

Mitigasi bencana alam tanah longsor sudah banyak dilakukan penelitian dengan berbagai metode sesuai kondisi lokasi penelitian. Penelitian dengan tujuan untuk memetakan angka keamanan lereng pernah dilakukan sebelumnya. Beberapa penelitian yang pernah dan berkaitan dengan pemetaan angka keamanan lereng dijabarkan pada paragraph selanjutnya.

Penelitian tentang pemanfaatan data digital elevation model (DEM) untuk pemetaan angka keamanan lereng di Bukit Ganoman, Kecamatan Matesih, Kabupaten Karanganyar, Jawa Tengah. Data DEM yang digunakan berupa data ASTER GDEM yang kemudian diolah untuk mengetahui variasi kemiringan lereng. Perhitungan stabilitas lereng menggunakan metode Morgenstern-Price dengan bantuan software GeoSlope, kemudian dilakukan analisa statistik dengan konsep interval kepercayaan untuk mendapatkan nilai stabilitas lereng pada setiap tingkat keyakinan. Output dari penelitian ini berupa peta stabilitas lereng (Wicaksono, dkk. 2016).

Penelitian yang serupa dengan Wicaksono adalah penelitian tentang stabilitas lereng dengan pemanfaatan data Peta Rupa Bumi Indonesia (RBI) untuk mengetahui variasi kemiringan lereng. Perhitungan kemiringan lereng menggunakan metode Circle. Perhitungan stabilitas lereng menggunakan bantuan software GeoStudio 2007 (Slope/W), kemudian dilakukan perhitungan prosentase tingkat kepercayaan untuk memperoleh nilai stabilitas lereng pada setiap tingkat keyakinan. Output dari penelitian ini berupa peta stabilitas lereng (Adriyati, dkk. 2016).

\section{DASAR TEORI}

\section{Longsoran}

Longsoran adalah pergerakan massa tanah maupun batuan pada suatu bidang longsor. Pergerakan massa tanah ini merupakan gerakan melorot ke bawah yang berupa material pembentuk lereng, yaitu dapat berupa tanah, tanah timbunan, batu atau campuran dari material lainnya. Bila gerakan massa tanah ini sangat berlebihan, maka disebut sebagai tanah longsor (landslide) (Hardiyatmo, 2012).

\section{Interval Kepercayaan}

Interval kepercayaan (confidence interval) adalah kisaran nilai yang dibuat dari data sampel dimana parameter populasi cenderung terjadi dalam kisaran tersebut dengan probabilitas sesuai yang spesifik (Douglas A Lind, 2007).

Tingkat kepercayaan pada dasarnya menunjukkan sejauhmana pengambilan keputusan mengenai hasil uji hipotesis nol diyakini kebenarannya. Dalam statistika, tingkat kepercayaan nilainya berkisar antara 0 sampai 100\% dan dilambangkan oleh $1-\alpha$. Secara konvensional, para peneliti dalam ilmu-ilmu sosial sering menetapkan tingkat kepercayaan berkisar antara 95\% - 99\%. Jika dikatakan tingkat kepercayaan yang digunakan adalah 95\%, ini berarti tingkat kepastian statistik sampel mengestimasi dengan benar parameter populasi adalah $95 \%$, atau tingkat keyakinan untuk menolak atau mendukung hipotesis nol dengan benar adalah 95\% (Sambas Ali Muhidin, 2013). Rumus yang digunakan untuk analisa statistik ini dapat dilihat pada Persamaan 1 hingga Persamaan 3.

$$
\begin{aligned}
& \bar{x}=\mu=\frac{\sum_{i=1}^{n} x_{i}}{n}=\frac{x_{1}+x_{2}+\cdots+x_{n}}{n} \\
& \sigma=\sqrt{\frac{\sum_{i=1}^{n}\left(x_{i}-\mu\right)^{2}}{n-1}} . \\
& \bar{x}-t_{(\alpha)} \frac{\sigma}{\sqrt{n}}<\mu
\end{aligned}
$$

keterangan :

$$
\begin{aligned}
\mu=\bar{x} & =\text { rata-rata, } \\
\bar{x}_{n} & =\text { data ke-n, } \\
\mathrm{n} & =\text { jumlah sampel, } \\
\sigma & =\text { standar defiasi, } \\
t & =\text { tabel Distribution Critical V alues, } \\
\alpha & =\text { tingkat signifikan data. }
\end{aligned}
$$

\section{Analisa Data Hujan}

Data hujan sebelum digunakan harus terlebih dahulu dilakukan uji homogenitas untuk membuktikan bahwa data hujan tersebut layak digunakan untuk analisa. Data hujan yang digunakan pada penelitian ini adalah data hujan pada tahun 2015 dan 2016. Metode RAPS digunakan untuk uji homogenitas pada penelitian ini. Metode RAPS membandingkan niai hitung dengan nilai kritik pada nilai Confidence Interval yang sesuai. Jika nilai kritik $>$ nilai hitung, maka data tersebut homogen. Sedangkan jika nilai kritik $<$ nilai hitung, maka data tersebut ti- 
dak homogen sehingga untuk dapat digunakan pada analisa data outlier (nilai ekstrim) harus diganti dengan nilai rerata atau batas atas/bawah (Haan, 1977).

Setelah uji homogenitas maka data hujan dirubah menjadi data hujan wilayah dengan metode rerata aljabar. Metode rerata aljabar dapat digunakan jika jarak antar stasiun kurang dari $30 \mathrm{~km}$. Dalam Sistem Drainase Perkotaan yang Berkelanjutan (Suripin, 2004) untuk mencari hujan wilayah dengan metode rerata aljabar dapat dilihat pada Persamaan 4.

$$
P=\frac{P_{1}+P_{2}+P_{3}+\ldots+P_{n}}{n}
$$

Keterangan :

$$
\begin{aligned}
& P \quad=\text { curah hujan wilayah, } \\
& P_{1}, P_{2}=\text { curah hujan di pos penakar hujan } 1 \text { dan } 2, \\
& P_{n} \quad=\text { curah hujan di pos penakar hujan }-\mathrm{n}, \\
& n \quad=\text { jumlah pos penakar hujan. }
\end{aligned}
$$

Data hujan wilayah yang masih berupa data hujan harian, kemudian diolah menjadi data hujan dua harian. Dari data hujan wilayah dua harian tersebut kemudian dicari nilai maksimum yang pernah terjadi selama tahun 2015 dan 2016. Data hujan wilayah dua harian maksimum tersebut kemudian diolah menjadi data intensitas hujan. Rumus yang digunakan untuk intensitas hujan adalah metode Mononobe yang dapat dilihat pada Persamaan 5.

$$
I=\frac{R_{24}}{24}\left(\frac{24}{t}\right)^{\frac{2}{3}}
$$

Keterangan :

$I=$ intensitas curah hujan untuk lama hujan $\mathrm{t}(\mathrm{mm} / \mathrm{jam})$,

$t \quad=$ lamanya curah hujan (jam),

$\mathrm{R}_{24}=$ curah hujan maksimum selama $24 \mathrm{jam}(\mathrm{mm})$.

Besaran $t$ ditentukan berdasarkan rata-rata lama curah hujan maksimum yang terjadi dalam satu hari pada lokasi penelitian (Kalimanto, 2015). Di Kabupaten Karanganyar pernah terjadi hujan dengan durasi maksimum 6 jam (Nurhidayah, 2010). Jadi karena penelitian ini berlokasi di Karanganyar maka $t$ yang digunakan adalah 6 jam.

\section{Analisa Kedalaman Tanah Jenuh dengan Metode Green-Ampt}

Metode Green-Ampt merupakan metode yang digunakan untuk melakukan pendugaan kapasitas dan laju infiltrasi. pada tahun 2006 Chen dan Young melakukan penelitian untuk memodifikasi persamaan metode infiltrasi Green-Ampt agar dapat digunakan pada permukaan miring, sehimgga laju infiltrasi pada lereng dapat dihitung menggunakan metode Green-Ampt. Persamaan Green-Ampt menurut dilihat pada Persamaan 6 dan Persamaan 7 (Chen dan Young, 2006).

$$
\begin{aligned}
& t=\frac{F(t)}{p \cos \alpha} \text { untuk } F(t)<F_{p} \text { dan } t<t_{p} \text { atau } p<k \\
& H_{\text {sat }}=\frac{F(t)}{\left(\theta_{s}-\theta_{t}\right)}
\end{aligned}
$$

Keterangan :

$F(t)=$ infiltrasi kumulatif $(\mathrm{cm})$,

$H_{\text {sat }}=$ tebal tanah jenuh $(\mathrm{cm})$,

$k=$ koefisien permeabilitas $(\mathrm{cm} / \mathrm{jam})$,

$t \quad=$ lama hujan,

$a \quad=$ sudut kemiringan lereng (derajat),

$\theta_{s}=$ kelembaban tanah jenuh,

$\theta_{t}=$ kelembaban tanah awal sebelum terjadi infiltrasi.

Nilai konduktivitas dan suction head ditentukan berdasarkan Tabel 1. 
Tabel 1 Parameter infiltrasi Green-AMpt untuk berbagai jenis tanah (Rawles, dkk, 1983)

\begin{tabular}{lccccc}
\hline Texture & $\begin{array}{c}\text { Porosity } \\
(\eta)\end{array}$ & $\begin{array}{c}\text { Residual } \\
\text { Porosity } \\
\left(\theta_{r}\right)\end{array}$ & $\begin{array}{c}\text { Effective } \\
\text { Porosity }\end{array}$ & $\begin{array}{c}\text { Suction } \\
\boldsymbol{H e a d} \\
\left(\theta_{e}\right)\end{array}$ & $\begin{array}{c}\text { Conductivity } \\
\boldsymbol{k}(\mathbf{c m} / \mathbf{h r})\end{array}$ \\
\hline Sand & 0,437 & 0,020 & 0,417 & 4,95 & \\
\hline Loamy Sand & 0,437 & 0,036 & 0,401 & 6,13 & 2,99 \\
\hline Sandy Loam & 0,453 & 0,041 & 0,412 & 1,01 & 1,09 \\
\hline Loam & 0,463 & 0,029 & 0,434 & 8,89 & 0,34 \\
\hline Silt Loam & 0,501 & 0,015 & 0,486 & 16,68 & 0,65 \\
\hline Sandy Clay & 0,398 & 0,068 & 0,330 & 21,85 & 0,15 \\
Loam & & & & & 0,10 \\
\hline Clay Loam & 0,464 & 0,155 & 0,309 & 20,88 & 0,10 \\
\hline $\begin{array}{l}\text { Silty Clay } \\
\text { Loam }\end{array}$ & 0,471 & 0,039 & 0,432 & 27,30 & 0,06 \\
\hline Sandy Clay & 0,430 & 0,109 & 0,321 & 23,90 & 0,03 \\
\hline Clay & 0,475 & 0,090 & 0,385 & 31,63 & \\
\hline
\end{tabular}

Analisa Stabilitas Lereng dengan Metode Morgenstern-Price

Analisa stabilitas lereng didasarkan pada konsep keseimbangan batas plastis. Adapun maksud analisis stabilitas lereng adalah untuk menentukan faktor aman dari bidang longsor yang potensial. Faktor aman didefinisikan dengan memperhatikan tegangan geser rerata sepanjang bidang longsor potensial, dan kuat geser tanah rerata sepanjang permukaan longsoran.

Metode Morgenstern-Price (Morgenstern dan Price, 1965) dikembangkan terlebih dahulu daripada metode kesetimbangan batas umum. Metode ini dapat digunakan untuk semua bentuk bidang runtuh dan telah memenuhi semua kondisi kesetimbangan. Metode Morgenstern-Price menggunakan asumsi yang sama dengan metode kesetimbangan batas umum yaitu terdapat hubungan antara gaya geser antar irisan dan gaya normal antar-irisan, yang dapat dilihat pada Persamaan 8.

$$
X=E \lambda f(x)
$$

Keterangan :

$$
\begin{array}{ll}
X & =\text { gaya geser antar irisan } \\
E & =\text { gaya normal antar irisan } \\
\lambda & =\text { persentase dari fungsi yang digunakan, } \\
f(\mathrm{x}) & =\text { suatu fungsi. }
\end{array}
$$

Nilai dari asumsi yang tidak diketahui dalam metode Morgenstern-Price adalah Safety Factor (SF), faktor pengali $(\lambda)$, dan gaya normal yang bekerja pada dasar bidang irisan $(N)$. Dari hasil analisa dengan kesetimbangan maka $f(x)$ dapat diketahui, dan komponen gaya geser yang bekerja di sekitar bidang irisan $(X)$ dapat dihitung dengan persamaan 9. Gaya-gaya yang bekerja pada bidang irisan pada metode Morgenstern-Price di software GeoStudio Slope/W dapat dilihat pada Gambar 1. 


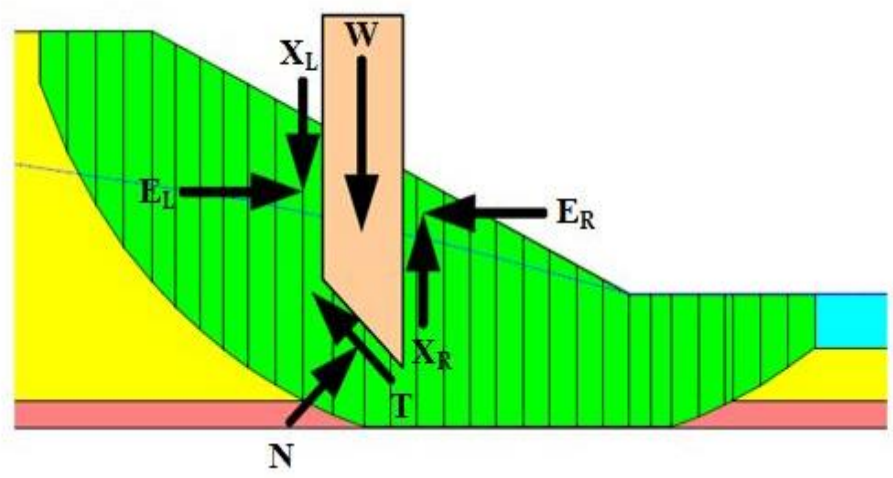

Gambar 1. Gaya-gaya yang Bekerja pada Bidang Irisan

Metode Morgenstern-Price (Stability Modeling with Slope/W)

$N=\frac{\left[W-\left(X_{R}-X_{L}\right) \frac{c^{\prime} \sin \alpha-u \tan \phi^{\prime} \sin \alpha}{F}\right]}{\cos \alpha+\frac{\sin \alpha \tan \phi^{\prime}}{F}}$

Keterangan :

$N=$ gaya normal di dasar irisan,

$c^{\prime}=$ kohesi (jika analisis dalam kondisi undrained diambil nilai $\mathrm{Cu}$, jika dalam kondisi drained diambil nilai kohesi efektif),

$W \quad=$ gaya akibat beban tanah,

$\alpha=$ sudut antara titik tengah bidang irisan dengan titik pusat busur bidang longsor,

$\phi^{\prime} \quad=$ sudut geser tanah (jika dalam kondisi undrained nilai sudut geser 0 ),

$u=$ tekanan air pori,

$\mathrm{X}_{\mathrm{l}}, \mathrm{X}_{\mathrm{r}}=$ gaya gesek yang bekerja di tepi irisan.

Pada metode ini analisa faktor keamanan dilakukan dengan dua prinsip yaitu kesetimbangan momen $\left(F_{m}\right)$ dan kesetimbangan gaya $\left(F_{f}\right)$. Faktor keamanan dari prinsip kesetimbangan momen $\left(F_{m}\right)$ dan kesetimbangan gaya $\left(F_{f}\right)$ untuk bidang kelongsoran circular dapat dilihat di Persamaan 10 dan Persamaan 11.

$$
\begin{aligned}
F_{m} & =\frac{\sum\left[c^{\prime} \beta R+(N-u \beta) \tan \phi^{\prime}\right]}{\sum W x-\sum N f \pm \sum D d} \\
F_{f} & =\frac{\sum\left[c^{\prime} \beta \cos \alpha+(N-u \beta) \tan \phi^{\prime} \cos \alpha\right]}{\sum N \sin \alpha-\sum D \cos \omega}
\end{aligned}
$$

digunakan untuk analisa kedalaman tanah jenuh dengan metode Green-Ampt dengan data kemiringan lereng yang diperoleh dari peta ASTER GDEM, dan data intensitas hujan yang telah diperoleh sebelumnya. Kemudian dilakukan analisa stabilitas lereng dengan software GeoStudio Slope/w metode Morgenstern-Price. Hasil analisa stabilitas lereng yang berupa nilai SF kemudian dipetakan menggunakan software GRASS GIS.

Keterangan :

$c^{\prime} \quad=$ kohesi (jika analisis dalam kondisi undrained diambil nilai $\mathrm{Cu}$, jika dalam kondisi drained diambil nilai kohesi efektif),

$\phi^{\prime} \quad=$ sudut geser tanah (jika dalam kondisi undrained nilai sudut geser 0 ),

$u=$ tekanan air pori,

$N \quad=$ gaya normal di dasar irisan,

$W \quad=$ gaya akibat beban tanah,

$D \quad=$ tumpuan beban titik

$\beta, R, x=$ parameter geometri

$a \quad=$ sudut di dasar irisan.

Analisa stabilitas lereng menggunakan metode Morgenstern-Price dengan bantuan software GeoStudio Slope/w. Software ini merupakan program yang menggabungkan dua persamaan faktor keamanan yaitu gaya keseimbangan dan momen irisan. Dari hasil akhir program Slope/w menghasilkan besaran nilai faktor keamanan suatu lereng dan mengetahui bagaimana kondisi stabilitas lereng tersebut, sehingga diharapkan mampu menyelesaikan masalah-masalah geoteknik yang berkaitan dengan stabilitas lereng maupun tanah. Slope/w terdiri dari tiga bagian 
pengerjaan, yaitu: Define untuk mendefinisikan model lereng, Solve untuk menganalisa hasil perhitungan, Contour untuk memperlihatkan gambaran hasil perhitungan.

\section{Pemetaan $\boldsymbol{S F}$}

Pemetaan SF merupakan pembuatan peta yang memuat nilai angka keamanan lereng setiap koordinat $x$ dan $y$. Pemetaan SF pada penelitian ini menggunakan bantuan software GRASS GIS dan Microsoft Excel. Proses pembuatan peta $S F$ yaitu semua nilai Safety Factor $(S F)$ yang telah diperoleh dari analisa stabilitas lereng dituliskan ke dalam file dengan format .csv dengan bantuan software Microsoft Excel. File dengan format .csv tersebut berisi koordinat longitude $(x)$ pada kolom satu, kemudian koordinat lattitude (y) pada kolom 2, dan nilai Safety Factor (SF) pada kolom 3. File .csv tersebut kemudian diimpor ke software GRASSGIS, lalu ditindihkan ke peta dasar RBI.

\section{METODOLOGI PENELITIAN}

Metode yang digunakan pada penelitian ini antara lain sebagai berikut. Data hujan (Dari januari 2015 hingga Desember 2016) berupa data hujan titik yang diperoleh dari Balai Pekerjaan Umum Sumber Daya Air dan Penataan Ruang Bengawan Solo Surakarta, dilakukan uji homogenitas dengan metode RAPS. Jika terbukti homogen, kemudian diolah menjadi data hujan wilayah dengan metode rerata aljabar. Kemudia hujan wilayah harian diolah menjadi hujan wilayah dua harian dan dicari data hujan maksimal. Data hujan wilayah dua harian maksimal tersebut kemudian diolah menggunakan metode Mononobe untuk memperoleh data intensita hujan.

Langkah berikutnya yaitu mengolah data tanah. Data tanah didapatkan dari uji lab (data primer) dan data tanah dari penelitian sebelumnya (data sekunder) berupa data fisik dan mekanik tanah. Data tanah ini kemudian

\section{HASIL DAN PEMBAHASAN}

Hasil dari penelitian ini berupa Peta Safety Factor $(S F)$ bukit Ganoman, Desa Koripan, Kecamatan Matesih, Kabupaten Karanganyar yang dapat dilihat pada Gambar 2.

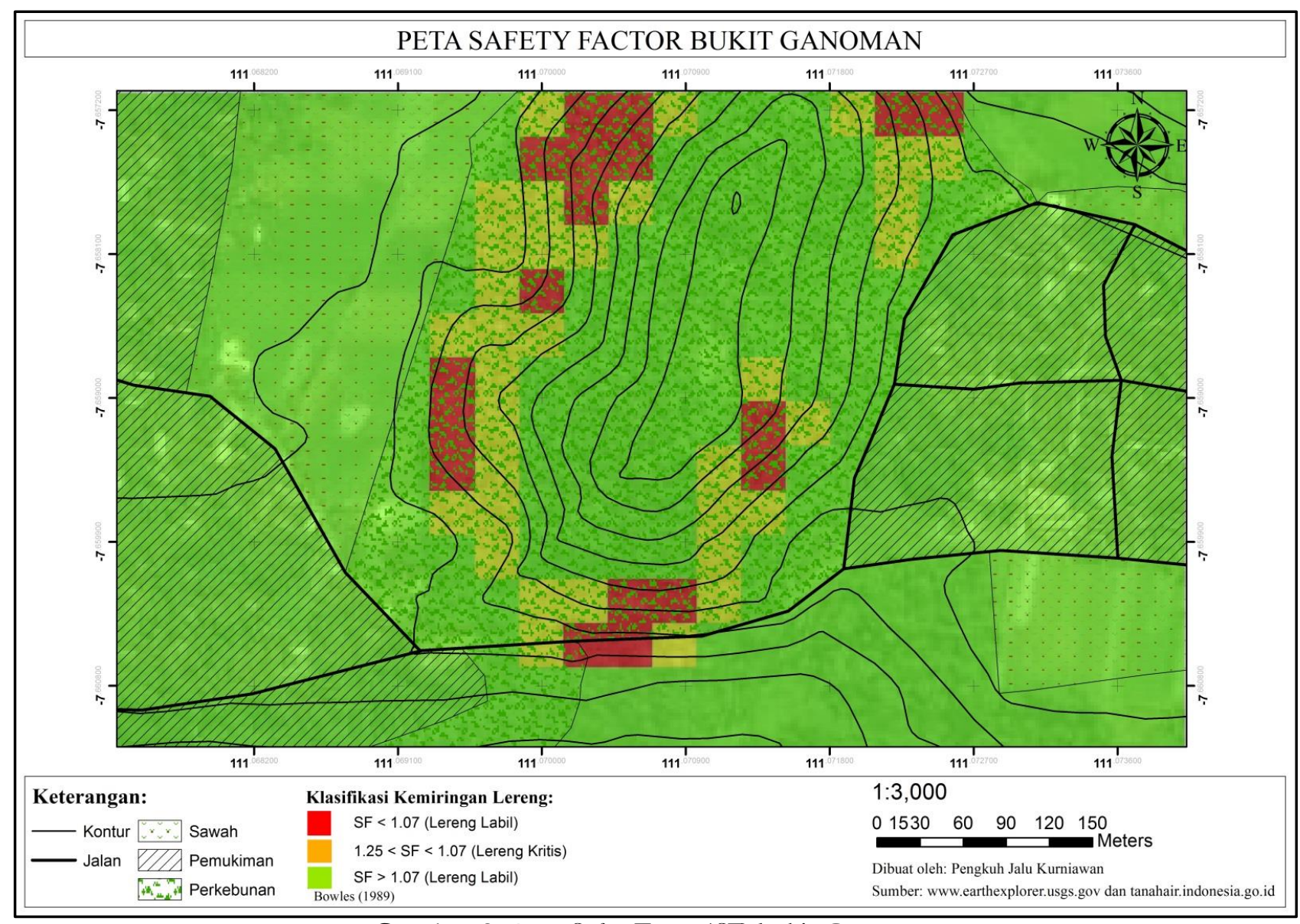

Gambar 2. Peta Safety Factor (SF) bukit Ganoman

Hasil Peta SF menunjukkan bahwa daerah Bukit Ganoman yang memiliki potensi kejadian longsor cukup besar yaitu daerah dengan kondisi lereng labil (SF kurang dari 1,07) berada pada daerah perkebunan dan ada yang melalui badan jalan di kaki Bukit Ganoman. Daerah badan jalan yang diberi kotak merah adalah lokasi longsor pada 5 Februari 2016. 


\section{KESIMPULAN}

Dari penelitian ini dapat diterik kesimpulan sebagai berikut:

1. Hasil Peta $S F$ menunjukkan bahwa bukit Ganoman memiliki beberapa titik yang bisa atau sering terjadi longsor (lereng labil dengan $S F<1,07$ ), pernah terjadi longsor (lereng kritis dengan 1,07 $<S F<1,25$ ), dan jarang terjadi longsor (lereng stabil dengan $S F>1,25$ ).

2. Daerah lereng labil yang berada di badan jalan pernah terjadi longsor pada 5 februari 2016 sehingga penelitian ini terbukti cukup valid.

\section{UCAPAN TERIMAKASIH}

Terima kasih saya ucapkan kepada Bapak R. Harya Dananjaya H.I ST, M.Eng dan Dr. Ir. Rr. Rintis Hadiani, M.T., yang telah membimbing, memberi arahan dan masukan dalam penelitian ini.

\section{REFERENSI}

Adriyati, M., dkk., 2016. Analisis Stabilitas Lereng Menggunakan Software Geo Studio 2007 dengan Variasi Kemiringan (Studi Kasus: Bukit Ganoman Kab Karanganyar). E-Jurnal Matriks Teknik Sipil/Maret 2017/97. Surakarta: UNS.

Bowles, E., J., 1989. Sifat-sifat Fisis dan Geoteknis Tanah. Jakarta: PT. Erlangga.

Chen, L., dan Young, M., H., 2006. Green-Ampt Infiltration Model for Sloping Surfaces. Water Resources Research, Vol. 42, W07420. Las Vegas: Division of Hydrologic Sciences, Desert Research Institue.

Douglas, A., 2012. Teknik-teknik Statistika dalam Bisnis dan Ekonomi Menggunakan Kelompok Data Global. Jakarta: Salemba Empat.

GEO-SLOPE International, 2015. Stability Modeling with Slope/W.

Haan, C., T., 1977. Statistical Methods in Hydrology. Iowa: The Iowa State University Press.

Hardiyatmo, H., C., 2010. Mekanika Tanah 1. Yogyakarta: UGM Press.

Kalimanto, D., dkk., 2015. Analisis Stabilitas Lereng Akibat Beban Hujan Harian Maksimum Bulanan dan Beban Lalu Lintas. E-Jurnal Matriks Teknik Sipil/Juni 2016/458. Surakarta: UNS.

Nurhidayah, R., dkk., 2010. Kajian Angkutan Sedimen pada Sungai Bengawan Solo (Serenan-Jurug). E-Jurnal Matriks Teknik Sipil/Juni 2013/69. Surakarta: UNS.

Rawls, W., J., dkk., 1983. Green-Ampt Infiltration Parameters from Soils Data. Inggris: J. Hydraul.

Muhidin, Ali., S. 2013. http://sambas.staf.upi.edu/2013/01/22/tingkat-signifikansi-dan-tingkat-kepercayaan/. Diakses 28 Januari 201809.56 WIB

Suripin, 2004. Sistem Drainase Perkotaan yang Berkelanjutan. Yogyakarta: Andi Offset.

Tawakkal, M. Z., dkk., 2016. Pengarub Curah Hujan Harian Maksimum Bulanan Terhadap Stabilitas Lereng (Studi Kasus: Desa Mangunharjo, Jatipurno, Wonogiri). E-Jurnal Matriks Teknik Sipil/Juni 2016/445. Surakarta: UNS.

Triatmodjo Bambang, 2008. Hidrologi Terapan. Yogyakarta : Beta Offset.

Wicaksono, N., M., dkk., 2016. Pemanfaatan Data Digital Elevation Model (DEM) untuk Pemetaan Angka Keamanan Berdasarkan Resiko Longsor dari Tinjauan Geoteknik. E-Jurnal Matriks Teknik Sipil/Maret 2017. Surakarta: UNS. 